\title{
MOISTURE AT CONTACTS OF TIMBER-CONCRETE ELEMENT
}

\author{
Roman Fojtík, Lenka Kubíncová, Viktor Dubovský, \\ Kateřina Kozlová \\ Všb - Technical University of Ostrava \\ Czech Republic
}

(Received April 2020)

\begin{abstract}
The subject of the article is to monitor the changes of moisture on the contact surface concrete and timber part of the composite timber-concrete beam. The moisture directly affects the properties of timber and causes its volume changes and degradation processes. These effects reduce of durability and load capacity of the structures. The beam was placed at the exterior. The observed contacts of the beam are often critical on real structures, as it is difficult to repair and maintenance in the case of increasing moisture or intrusion of dirt. The experiment was used to monitor and evaluate the dependence of changing moisture in contacts depending on ambient environmental conditions.
\end{abstract}

KEYWORDS: Timber-concrete, composite, moisture, prestressed, temperature, bridge, footbridge.

\section{INTRODUCTION}

In the constructional practice, timber bridge structures are increasingly encountered (Duwadi and Ritter 1997, Ritter 2005, Fojtík et. all 2017). A problem area of use of timber as material for the construction of bridges is the degradation of wood mass caused by the ambient environmental conditions (Vašková et al. 2016, Reinprecht 2016, Vašková et al. 2017, Björngrim et. al 2016). For this reason, structures are treated with various preparations or used in combination with other materials, which are intended to protect the timber part from weather conditions (Bak et al. 2012, Dias et al. 2015). This initiative is one of the reasons for the development of composite timber -concrete structures (Fig. 1).

The climatic conditions are directly related to the overall load-bearing capacity and durability of the structure. Moisture that accumulates in timber can cause its degradations and reduce loadbearing capacity. The article focuses on the moisture at the contact between prestressed timber elements and concrete bridge deck, which changes depending on the climatic conditions of the environment (Fortino et. al 2013, Fortino et. al 2019). 


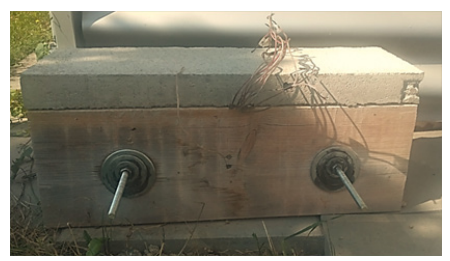

Fig. 1: Experimental sample of composite timber-concrete beam.

Composite timber-concrete structures are increasingly occurring in the construction of bridge structures (Lyu et. al 2017, Bajcezerová and Kanócz 2016). This is evidenced by an overview of the use of this construction system in different geographical areas and climates (Rodrigues, Dias and Providencia 2013). The overall rigidity and load-bearing capacity of the composite timber-concrete structural system also depends on the impact of climatic conditions. Many research and publications deal the material properties of timber and concrete and their balance (Toratti 1992, Hanhijärvi 1995, Gutkowski et. al 2008). The research realized by a group of authors confirmed the theory of decrease in the load-bearing capacity of the structural systems in relation to moisture and ambient temperature (Kanócz and Bajzecerová 2014). Various publications deal with a brief overview of the state of moisture measured on bridge structures and the load-bearing capacity of current and historic bridges (Fojtík 2019).

\section{MATERIAL AND METHODS}

For the purpose of the experimental measurement, experimental samples were created, the schematic representation of which is shown in Fig. 2. These are therefore scaled-down models of transversely prestressed composite timber-concrete beams. The timber used is spruce lumber with a grade of $\mathrm{C} 24$. The pieces of timber used were without signs of damage and drying cracks. As a coupling means, special screws for coupling timber to concrete VB - $48-7.5 \mathrm{x} 100$ DUROCOAT (KILLICH s.r.o.) have been used, always placed in pairs in a cross at the angle $45^{\circ}$. The concrete deck was made of material C25/30 with height $60.0 \mathrm{~mm}$. Mutual prestressing of timber elements was realized by high-strength threaded rod of diameter M16, strength class 12.9. High-strength rods are on both sides equipped with specially made bearing plates and nuts of the same strength class as prestressing elements themselves.

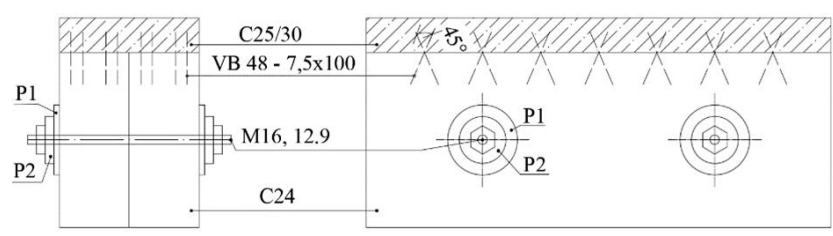

Fig. 2: Schematic display of experimental samples.

As already mentioned, the article focuses on moisture at the contact of the concrete bridge deck and timber main beams. The monitoring was performed using surface moisture sensors placed on each of the prestressed timber beams and recorded using a data logger and ALMEMO 
710 sensor. The values were monitored within the period from 26.9.2018 to 30.9.2019. The article is aimed at monitoring moisture changes on the beam placed in the exterior.

The method of linear regression a correlation was used to determine the relationship between moisture in the contact of timber beams and concrete deck and moisture in contact between prestressed timber beams and climatic conditions (Fragiacomo and Davies 2011). Correlation statistics determine whether there is a correlation between variables and, if so, what its strength is. The first measure used in linear analysis was covariance, which was used to confirm or rebut an existing linear dependence (correlation). Covariance is calculated using a relationship:

$$
\operatorname{cov}_{x y}=\frac{1}{N} \sum\left(x_{i}-\bar{x}\right)\left(y_{i}-\bar{y}\right)
$$

The calculation determines whether it is a linear relationship (negative, positive) or not a linear relationship. Subsequently, a model of simple linear regression was created using the method of least squares and the parameters of the linear regression model are estimated.

\section{RESULTS AND DISCUSSION}

Timber is a hygroscopic material and is always influenced by the surrounding environmental and climatic conditions. An important factor that affects the durability of timber is the relative humidity of the environment. During the diagnostics on bridge structures, the measured value is the absolute humidity, which changes depending on the relative humidity. In the case of insufficient prevention and protection of structure moisture is absorbed by the wood, which affects the durability of the structure. Moisture accumulation occurs and biotic damage begins to appear, in Central Europe in particular, the presence of Gloeophyllum sepiarium and soft decomposition. In the case of transversely prestressed composition timber-concrete structures, timber is swelled and dried, which affects the change in prestress (Fojtík 2019, Fojtík et al. 2020, Quenneville and Dalen 1994).

Fig. 3 shows the partial course of moisture changes at the contact of the concrete deck and timber beams (sensor A and B) and changes in moisture values between timber beams (sensor C) overtime on a beam placed outdoors.
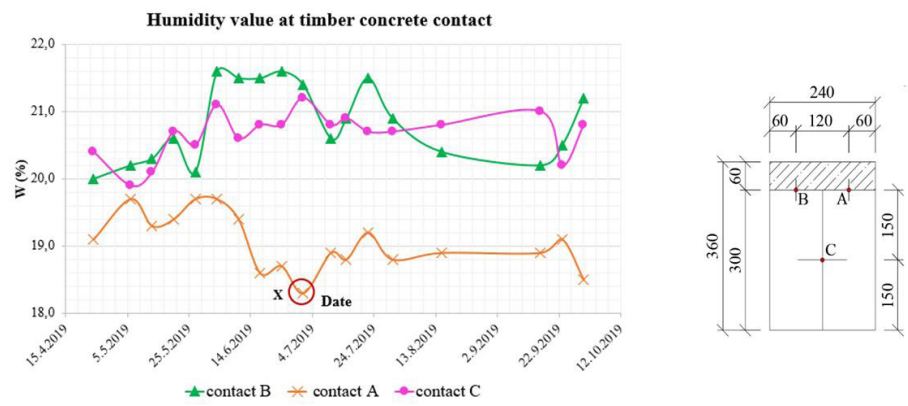

Fig. 3: Moisture changes in the experimental sample over time. 
Tab. 1: Moisture values (average, minimum, maximum) on monitored contacts - exterior.

\begin{tabular}{|c|c|c|c|c|}
\hline \multicolumn{2}{|c|}{} & $\mathrm{w}_{\text {average }}(\%)$ & $\mathrm{w}_{\min }(\%)$ & $\mathrm{w}_{\max }(\%)$ \\
\hline \multirow{3}{*}{ Beam - exterior } & $\mathrm{A}$ & 19.1 & 18.3 & 19.7 \\
\cline { 2 - 5 } & $\mathrm{B}$ & 20.8 & 20.0 & 21.6 \\
\cline { 2 - 5 } & $\mathrm{C}$ & 20.7 & 19.9 & 21.2 \\
\hline
\end{tabular}

This is a period from 25.04.2019 to 1.10.2019. This period has been selected as a reference because the timber reaches maximum moisture with maximum relative ambient temperature. This is a fact obtained by experimental monitoring on real bridge structures (Fig. 4). Fig. 4 shows the output of measurement on the bridge during the summer and winter months. It is obvious that in the case of the summer months, the higher the absolute humidity of the environment, the lower the moisture of the timber, and in the case of the winter period, the moisture content of the timber increase with increasing absolute humidity.
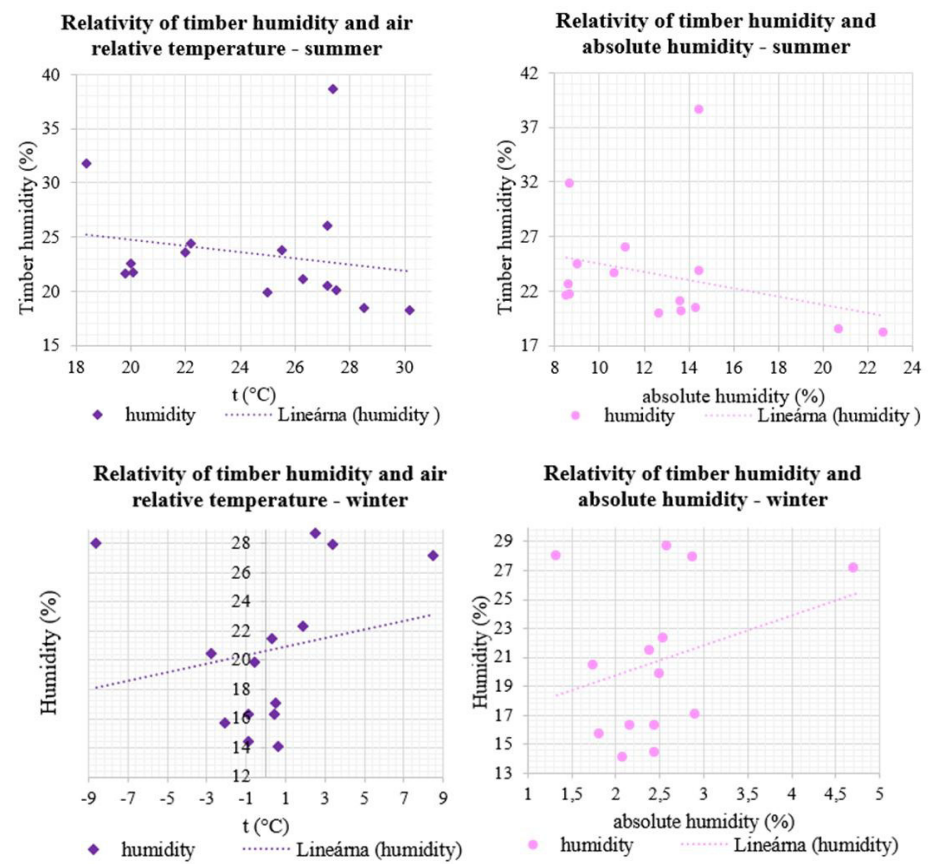

Fig. 4: Relationship between ambient conditions and timber moisture.

The course of moisture changes (Fig. 3) on the sensor marked A shows significantly lower moisture values than the moisture on the remaining sensors. The reason is the location of a beam. Sensor A (the course of changes in moisture is shown in the graph by the orange curve) is installed on the glaring side of the beam. The remaining sensors (shown in pink and green on the graph) are installed at the non-glare side of the experimental sample.

The extremes are visible on all curves. This is a relatively small change in moisture at the individual contacts. These deviations from the standards are caused either by periods of increases total rainfall or long-term extreme temperature fluctuations, where the air reached high relative 
humidity. For example, the orange curve shows point $\mathrm{X}$, where the value of the timber moisture decreases (sensor A). This is the period in the late June/early July that showed a very high temperature (Fig. 5 on the left) and low total rainfall (Fig. 5 on the right: light blue column). The data on temperature course, total rainfall and relative humidity are obtained from the public available rapporteur of the Czech Hydrometeorological Institute.
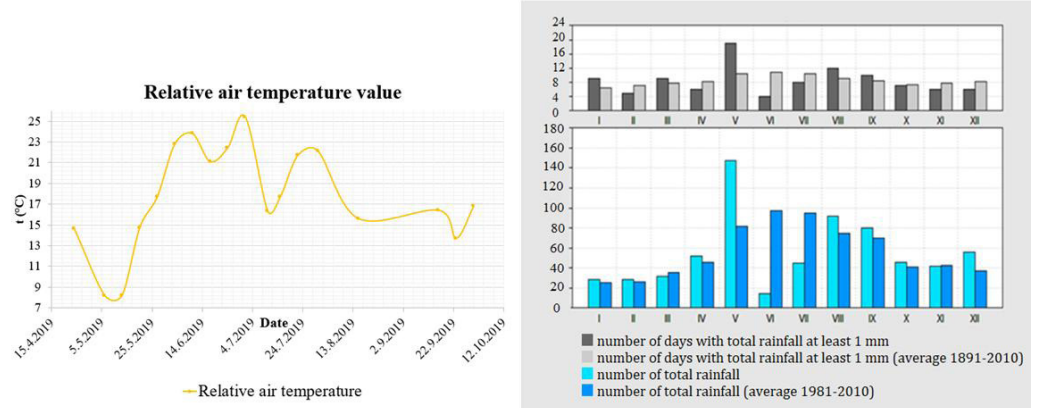

Fig. 5: From the left: The course of the relative ambient temperature over the observed period, the course of the monthly rainfall total during the observed period compared to the long-term average (Czech Hydrometeorological Institute 2019).

Fig. 6 shows the relationship between the moisture on the monitored contacts and the relative ambient temperature.

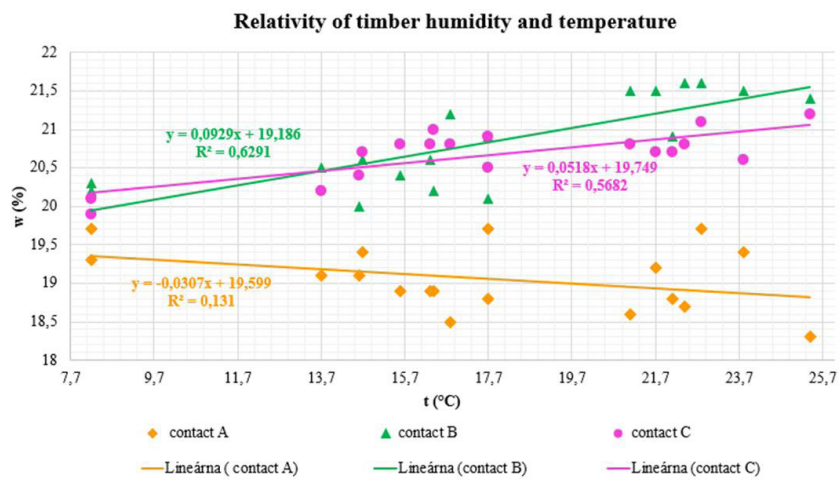

Fig. 6: Relationship between moisture and ambient temperature.

The pink color is the point dependence between the moisture at contact $\mathrm{C}$ and relative ambient temperature, the green color the dependence between the moisture at contact $\mathrm{B}$ and the relative ambient temperature, and the orange color is the dependence between the moisture at contact $\mathrm{A}$ and the relative ambient temperature. To confirm the existence of o linear dependence, a covariance was applied to the results. This confirmed that in the case of sensors B and C a positive linear covariance between the monitored parameters can be obtained and in the case of sensor A a negative linear covariance can be found. The dependence of monitored quantities in the contact $\mathrm{B}$ (shown green in the graph) and $\mathrm{C}$ (shown pink in the graph) shows a high correlation agreement (Hinkle et. all 1998). At contact B it is $R=0.79$ and in the case of contact 
$\mathrm{C}$ the correlation coefficient is $\mathrm{R}=0.75$. The correlation coefficients have been determined by regression analysis. In the case of contact $\mathrm{A}$, the correlation agreement is classified as low, as the correlation coefficient reaches the value $\mathrm{R}=0.36$ (Tab. 2).

Tab. 2: Statistical evaluation of the monitored parameters.

\begin{tabular}{|l|c|c|c|}
\hline \multirow{2}{*}{} & \multicolumn{3}{|c|}{ Monitored contact } \\
\cline { 2 - 4 } & $\mathrm{A}$ & $\mathrm{B}$ & $\mathrm{C}$ \\
\hline Covariance & -0.71 & 2.14 & 1.20 \\
\hline Covariance relationship & negative linear & positive linear & positive linear \\
\hline Coefficient of determination $\mathrm{R}^{2}$ & 0.13 & 0.63 & 0.57 \\
\hline Correlation coefficient R & -0.36 & 0.79 & 0.75 \\
\hline
\end{tabular}

The curve of the relative ambient temperature influences the moisture of the timber of the experimental beam in the monitored contacts. It is obvious that as the temperature increases, the moisture evaporates (contact A), i.e. the moisture of the wood decreases with increasing temperature. In contrast, in contacts $\mathrm{B}$ and $\mathrm{C}$, there is a transfer and heating, i.e. an increase in internal moisture under the concrete deck cover.

\section{CONCLUSIONS}

The hygroscopic properties of timber complicate its use in constructional practice. Thanks to research works and experience, there is now a lot of knowledge on how to protect timber properly, the extent to which it needs to be maintained and also that there are possibilities of applications of composite structures, in which the secondary material reduces the rate of degradation processes and creep of timber.

The subject of the research described in the article is the relationship between relative ambient temperature and moisture occurring in the contacts of the composite timber-concrete element. In this case, it is a contact between the timber main beams and concrete deck, and contact between the main timber beams, which are placed close together using prestressing elements, for a selected period.

In the case of sensors that are in a shaded area (sensor B and C), the covariance relationship between the monitored quantities proves to be positive linear. It means that with increasing relative ambient temperature, the humidity increases at the monitored locations. The statistical methods used showed high linear correlation between relative ambient temperature and moisture on the contacts. In the case of sensor A, the covariance relationship proved to be negative linear, i.e. with increasing relative temperature there is a decrease in moisture at this place, which supports the behavior of the timber depending on the ambient conditions during the summer months. This occurred due to the glare of this area of the experimental sample. Due to its action, the wood was dried out and the moisture increased in the places that were shaded. The moisture on the observed contacts was maintained at approximately the same value with very low dispersion. The knowledge gained through the experiment is very important in terms of composite timber-concrete structural systems and the durability of bridge structures. This allows to focus on problematic maintenance areas and possibility prevent damages caused by climate conditions during construction. 


\section{ACKNOWLEDGEMENTS}

This research was realized under financial support of Conceptual development of science, research and innovations IP2309911/2104 and Student Grant Competition VSB - TUO. The project registration number is SP2018/128.

\section{REFERENCES}

1. Bajcezerová, V., Kanócz, J., 2016: The effect of environment on timber. Concrete Composite Bridge Deck. Procedia Engineering 156: 32 - 39.

2. Bak, M., Yimmou, B.M., Csupor. K., Németh, R., Csóka, L., 2012: Enhancing the durability of wood agents wood destroying fungi using nano-zinc. In: International Science Conference on Suitable Development \& Ecological Footprint, Sopron, Hungary, 6 pp.

3. Björngrim, N., Hagman, O., Wang, X.A., 2016: Moisture content monitoring of a timber footbridge. BioResources 11(2): 3904-3913.

4. Dias, A.M.P.G, Ferreira, M.C.P., Jorge, L.F.C., 2015: Timber-concrete practical applications - bridge case study. Proceeding of the Institution of Civil Engineers - Structure Buildings 164(2): 131-141.

5. Duwadi S.R., Ritter, M.A., 1997: Timber bridges in the United States. Public Roads 60(3): 32-40.

6. Fojtík, R., 2019: Moisture content analysis of wooden bridges. Wood Research 64(3): 529-536.

7. Fojtík, R., Dědková, K., 2016: Analysis of diagnostic methods for detecting the presence of gloeophyllum SPP. Wood Research 61(4): 479-486.

8. Fojtík, R., Dubovský, V., Kozlová, K., Kubíncová, L., 2020: Prestress losses in spruce timber. Wood Research 65(4): 645 - 652.

9. Fojtík, R., Lokaj, A., Gabriel, J., 2017: Dřevěné mosty a lávky (Timber bridges and footbridges), ČKAIT, Praha. 158 pp.

10. Fortino, S., Genoese, A., Genoese, A., Nunes, L., Palma, P., 2013: Numerical modelling of hygro-thermal response of timber bridges during their service life: A monitoring case study. Construction and Buildings Materials 47: 1255-1234.

11. Fortino, S., Hradil, P., Metelli, G., 2019: Moisture-induced stress in large glulam beams. Case study: Vihantasalmi bridge. Wood Material Science and Engineering 14(3): 366-380.

12. Fragiacomo, M., Davies, M., 2011: Long-term behaviour of prestressed LVL members. II: analytical approach. Journal of Structural Engineering 137(12): 1562-1572.

13. Fragiacomo, M., Davies, M., 2011: Long-term behaviour of prestressed LVL members. I: experimental tests. Journal of Structural Engineering 137(12): 1553-1561.

14. Gutkowski, R, Brown, K., Shigidi, A., Natterer, J., 2008: Laboratory tests of composite wood-concrete beams. Construction and Building Materials 22(6): 1059 - 1066.

15. Hanhijärvi, A., 1995: Modelling of creep deformation mechanisms in wood: Dissertation. Helsinki, University of Technology, Technical Research Centre of Finland, 143 pp.

16. Hinkle, D.E., Wiersma, W., Jurs, S.G., 1998: Applied statistics for behavioural sciences (4th ed.). Chicago, IL: Rand McNally College Publishing, 209 pp.

17. Kanócz, J., Bajzecerová, V., 2014: Parametrical analysis of long-term behaviour of timberconcrete bended elements. Wood Research 59(3): 379-388. 
18. Lyu, Z., Málaga-Chuquitaype, C., Ruiz-Terab, A.M., 2017: Feasibility of timber-concrete composite road bridges with under-deck stay cables. IABSE Conference, Vancouver, Engineering the Future. Report 2017, Pp 268-275.

19. Quenneville, P., van Dalen, K., 1994: Relaxation behavior of prestressed wood assemblies. Part 1: Experimental study. Canadian Journal of Civil Engineering 21(5): 736-743.

20. Quenneville, P., Van Dalen, K., 1994: Relaxation behavior of prestressed wood assemblies. Part 2: Theoretical study. Canadian Journal of Civil Engineering 21(5): 744-751.

21. Reinprecht, L., 2016: Wood deterioration, protection and maintenance. John Wiley \& Sons Ltd, Chichester, UK. 376 pp.

22. Ritter, M.A., 2005: Timber bridges: Design, construction, inspection and maintenance. Part 1, Honolulu Hawaii: University Press of the Pacific, 478 pp.

23. Ritter, M.A., 2005: Timber bridges: Design, construction, inspection and maintenance. Part 2, Honolulu Hawaii: University Press of the Pacific, 453 pp.

24. Rodrigues, J.N., Dias, A., Providencia, P., 2013: Timber-concrete composite bridges: State of the art review. BioResources 8(4): $6630-6649$.

25. Toratti, T., 1992: Creep of timber beams in variable environment. PhD Thesis, Helsinki, University of Technology, Laboratory of Structural Engineering and Building Physics, $182 \mathrm{pp}$.

26. Vašková, V., Fojtík, R., Pustka, D., 2016: Monitoring and failures of footbridges made from glued laminated wood. Procedia Engineering 142: 87-91.

27. Vašková, V., Poništová, L., Fojtík, R., 2017: Vavrušová, K., Lokaj, A., Mikolášek, D., Fojtík, R., Žídek, L., 2016: Longitudinal glued joints of timber beams and the influence of quality manufacturing on to their carving capacity. Wood Research 61(4): 573-581.

\author{
Roman Fojtík*, Lenka Kubíncová, Viktor Dubovský, \\ Kateřina Kozlová \\ Vsb - Technical University of Ostrava \\ Faculty of Civil Engineering \\ Department of Building Constructions \\ Ludvika Podeste i875 \\ 70833 Ostrava \\ Czech Republic
}

*Corresponding author: roman.fojtik@vsb.cz 